\title{
Producing monoaromatic compounds from pyrolytic vapour of rice straw using $\mathrm{H}-\mathrm{ZSM}-5 / \mathrm{B}_{2} \mathrm{O}_{3}$ catalyst
}

\author{
Setiadi* $^{*}$ Raka Nugraha Wijaya, and Danestyan Arif Pradana \\ Department of Chemical Engineering, Faculty of Engineering, Universitas Indonesia, \\ Kampus Baru UI, Depok 16424, West Jawa, Indonesia
}

\begin{abstract}
The catalytic conversion of rice straw was done to produce mono aromatic compounds. The mixed catalyst of ZSM-5 and $\mathrm{B}_{2} \mathrm{O}_{3}$ was obtained through calcination of ZSM-5 and $\mathrm{H}_{3} \mathrm{BO}$ catalyst mixture. The variation of the composition of the ZSM-5 and $\mathrm{B}_{2} \mathrm{O}_{3}$ catalyst was applied in order to test the effect of catalyst composition to the production of mono aromatics compounds. The composition of catalyst used were $15 \%$ ZSM-5, 30\% ZSM-5, and 100\% ZSM-5. Other than the variation of catalyst composition, the variation of the operating temperature of the catalytic conversion also performed in order to study the effect of the temperature to the production of mono aromatic compounds. The catalytic conversion was done at 450,475 , and $500{ }^{\circ} \mathrm{C}$. Experimental results show that the addition of the catalyst resulted in the conversion of oxygenate compounds resulted from the pyrolytic process of rice straw into mono aromatic compounds. It also shows that using $100 \% \mathrm{ZSM}-5$ produced the highest yield of mono aromatics compounds. The amount of mono aromatic compounds produced will decrease, as the fraction of ZSM-5 catalyst used and operation temperature also decreased. Using the $100 \%$ ZSM-5, the mono aromatics compound with the highest yield is 1, 3 Dimethyl benzene or mxylene.
\end{abstract}

\section{Introduction}

Biomass as a renewable source undoubtedly plays an important role in the future because the main component is carbon and hydrogen with $\mathrm{H} / \mathrm{C}$ high enough comparing to other petroleum sources. But the high content of oxygen in biomass should be paid attention because it leads to lower the quality of final product after processing. Various processes may be employed to convert biomass into useful fuels and chemicals. Among those process, the conversion of biomass through a thermochemical process seems to show a promising alternative for many energy applications [1]. Pyrolysis is one of the most promising thermochemical process of converting biomass to fulfill the needs of bio fuels and chemicals [2].

The drawbacks of bio-oil from pyrolysis are high content of oxygen atom and various kind of oxygenated compounds making the low heating value and low stability which is the quality far enough from the product petroleum processing. Besides, the monoaromatic hydrocarbon in the bio-oil product in the tiny amount. So, to pave away the usage of biomass the catalytic conversion is one of the proven process that could be used to upgrade and improve the quality of the bio-oil. In this process, the biomass decomposed in the pyrolysis process, thermally decomposed the biomass producing pyrolytic vapors. Which then, the bio-oil being in form of the gaseous product could be directly upgraded using catalyst to refine the bio-oils into hydrocarbon or other intermediates [3]. With the presence of HZSM-5 catalyst, the vapor resulted from the decomposition of biomass consisting of various compound the oxygenate compounds, could be converted into mono aromatic compounds when they came in contact with the catalyst. For this work, in order to convert the biomass into mono aromatics compounds, ZSM-5 catalyst and the mixture of ZSM-5 and $\mathrm{B}_{2} \mathrm{O}_{3}$ with different composition was used. ZSM-5 catalyst is a catalyst with zeolite properties which have already proven to have the capability to convert oxygenated compounds into aromatics [4].

\section{Experimental Method}

There are total of three variations of ZSM-5 and $\mathrm{B}_{2} \mathrm{O}_{3}$ catalyst mixture. Those mixtures were $15 \%$ ZSM-5, 30\% ZSM-5, and 100\% ZSM-5. Other than the varied composition of catalyst, the catalytic conversion was done under three different operation temperature which were 450,475 , and $500^{\circ} \mathrm{C}$. These variations were applied in order to analysed and determine the most suitable mixture of catalyst and operation temperature to produce

Corresponding author: setiadi@che.ui.ac.id 
mono aromatic compounds.

\subsection{Material}

The type of biomass used as the feed for this experiment was rice straw. Before it can be used, the particle size of the rice straw was reduced to $1-3 \mathrm{~mm}$ using a grinder or grinding machine. Using an oven, the rice straw was then dried at the temperature of $60^{\circ} \mathrm{C}$ for around $5-6$ hours to reduce the water content of the rice straw to $<10 \%$ of the total mass. For this experiment, 1 gram of treated rice straw, 1 gram of mixture of catalyst, and 1 gram of quartz sand mixture was used for each experiment run.

The catalysts used for this experiment were ZSM-5 and boron oxide $\left(\mathrm{B}_{2} \mathrm{O}_{3}\right)$ catalyst with various compositions. The amount of catalyst used for catalytic conversion was 1 gram with different composition of ZSM-5 and $\mathrm{B}_{2} \mathrm{O}_{3}$ catalyst. If the amount of the catalyst was excessive weight, the bed of catalyst might block the pathway of the flowing products out of the tube, so there was no products could be collected. On the contrary, the experimental running with small amount of the catalyst, the catalytic conversion process resulted the bio-oil containing product in the difficulties to analytical detection.

The mixture of ZSM-5 and boron oxide $\left(\mathrm{B}_{2} \mathrm{O}_{3}\right)$ catalyst was prepared by physically mixing of boric acid $\left(\mathrm{H}_{3} \mathrm{BO}_{3}\right)$ as boron oxide precursor and ZSM-5 commercial catalyst. Then, the calcination process will be applied on the mixture at the atmospheric condition with the temperature of 300 and $600^{\circ} \mathrm{C}$ respectively for 2 hours each to get the supported boron oxide catalyst onto H-ZSM-5. $\mathrm{H}_{3} \mathrm{BO}_{3}$ was as the oxide precursor to decompose into water vapour and metabolic acid $\left(\mathrm{HBO}_{2}\right)$ at around $170{ }^{\circ} \mathrm{C}$, and further heating above $300^{\circ} \mathrm{C}$ will decomposed $\left(\mathrm{HBO}_{2}\right)$ to produce more steam and boron oxide $\left(\mathrm{B}_{2} \mathrm{O}_{3}\right)$ solids.

\subsection{Methods}

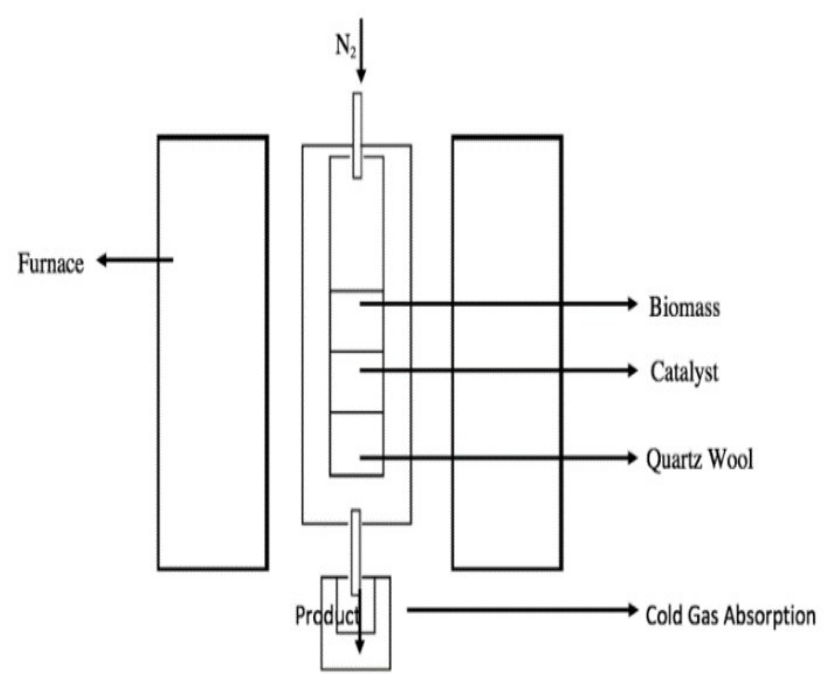

Fig. 1. Schematic diagram of experimental set-up apparatus for biomass catalytic pyrolysis
The conversion was done under atmospheric pressure, with the flow rate of $\mathrm{N}_{2}$ at around $40 \mathrm{ml} /$ minute, while the operation temperature was 450,475 , and $500{ }^{\circ} \mathrm{C}$. The reactor tube is $300 \mathrm{~mm}$ long, and $12 \mathrm{~mm}$ in diameter, which made from SS 316 which was the inert materials and was suitable for working in a high temperature environment. The tube was placed into an electric cylindrical shape furnace with an effort to put the rice straw and catalyst at the heating area where the heat is at the highest. Quartz wool was used at the lower end of the reactor tube to plugged the catalyst, preventing it to drop. The amount of the rice straw, catalyst, and quartz sand was one gram each. The high amount of the rice straw, catalyst, and quartz sand inside the reactor tube could lead to the reactor tube being clogged.

The schematic diagram of experimental equipment is shown in figure 1 . The pyrolysis pyrolysis of the rice straw, firstly the nitrogen gas was surely introduced into reactor for purging the possible air presence inside the reactor and as carrier gas function in flowing out the vapor product resulted from the pyrolytic decomposition process. And the vapor could be upgraded by employing the catalyst, the rice straw was placed over the mixture of catalyst and quartz sand as a fixed bed. This way, the vapor product of the decomposition of the rice straw should be upgraded when it flowed down through the layer of catalyst. The usage the stream of $40 \mathrm{ml} / \mathrm{mine} \mathrm{N}_{2}$, beside to push the downwards flow of the vapour product of the decomposition of rice straw to the layer of catalyst for the upgrading process, the function was also used to remove the air inside the reactor tube.

The product of the catalytic conversion resulted from the pyrolysis of rice straw and catalytic reaction was obtained by capturing the gaseous product in the bottom of the reactor. The gas produced from the catalytic conversion was trapped using cold absorption trap method with using acetone as the solvent. The gas that came out at the bottom of the reactor was maintained a direct contact with the solvent inside of a cold glass tube submerged in the ice-water bath kept near $1{ }^{\circ} \mathrm{C}$. Therefore, the gaseous products underwent the process of condensation and directly dissolved in the bulk of acetone solvent. The sample products dissolved were characterized for identifying and measuring the composition using GC-MS (Gas Chromatography Spectroscopy) instrument analysis.

\section{Experimental Results}

The catalysts used for this experiment was physically mixture of ZSM-5 and $\mathrm{B}_{2} \mathrm{O}_{3}$ catalyst. The catalyst composition used for this experiment were 15\% ZSM-5 $+85 \% \mathrm{~B}_{2} \mathrm{O}_{3}, 30 \%$ ZSM-5 $+70 \% \mathrm{~B}_{2} \mathrm{O}_{3}$, and $100 \%$ ZSM5 , and without catalyst. Beside catalyst, the catalytic conversion was conducted under different temperature. This experiment was conducted under the Temperature variation of $450^{\circ} \mathrm{C}, 475^{\circ} \mathrm{C}, 500^{\circ} \mathrm{C}$. Figure 2 through figure 4 show the product distribution resulted from catalytic conversion of rice straw for different composition of the ZSM-5 and $\mathrm{B}_{2} \mathrm{O}_{3}$ catalyst and 
different operation temperature.

Fig. 2 is result of the catalytic conversion under the temperature of $450{ }^{\circ} \mathrm{C}$, with the addition of mixture of $15 \%$ ZSM-5 and $85 \% \mathrm{~B}_{2} \mathrm{O}_{3}$ catalyst, the yield of mono aromatics compound produce increased from $0 \%$ to $15.95 \%$. After that, when the $30 \% \mathrm{ZSM}-5$ and $70 \% \mathrm{~B}_{2} \mathrm{O}_{3}$ catalyst was used, the yield of mono aromatics compound increased up to $23.11 \%$. When the $100 \%$ ZSM-5 catalyst was used, the yield of mono aromatics compound went up again to $53.88 \%$.

The same pattern can be seen in the result of sample of catalytic conversion under the temperature of $475^{\circ} \mathrm{C}$ (Fig. 3). When the $15 \%$ ZSM-5 and $85 \% \mathrm{~B}_{2} \mathrm{O}_{3}$ was added, it increased the production of mono aromatics compound by $19.85 \%$ from when there was no catalyst used which it produced $0 \%$ mono aromatics compound. The yield of monoaromatics compound increased again to $25.1 \%$ when the $30 \% \mathrm{ZSM}-5$ and $70 \% \mathrm{~B}_{2} \mathrm{O}_{3}$ was applied. After that, it went up again to $64.22 \%$ when the $100 \%$ ZSM- 5 was used.

The catalytic conversion under the temperature of $500^{\circ} \mathrm{C}$ (Fig. 4) shows that with the addition of $15 \%$ ZSM-5 and $85 \% \mathrm{~B}_{2} \mathrm{O}_{3}$ there are an increase of $26.66 \%$ of mono aromatics compound from $0 \%$ in which the catalyst was not present during the catalytic conversion process. Then, the usage of $30 \% \mathrm{ZSM}-5$ and $70 \% \mathrm{~B}_{2} \mathrm{O}_{3}$ catalyst pushed the yield of mono aromatics compound to $48.26 \%$. After that it went drastically to $79.09 \%$ when the $100 \%$ ZSM-5 catalyst was applied. It shows that with the addition of ZSM-5 $+\mathrm{B}_{2} \mathrm{O}_{3}$, it helps the process to produce mono aromatics. With the increasing fraction of ZSM-5, it will also increase the yield of mono aromatics produced from the result of catalytic conversion.

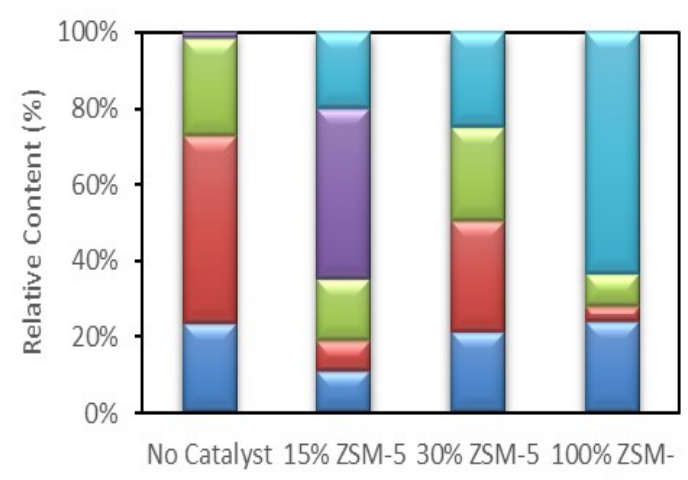

5

Fig. 2. Product distribution from catalytic conversion of biomass over three different composition of $Z \mathrm{ZM}-5 / \mathrm{B}_{2} \mathrm{O}_{3}$ catalysts: $15 \%$ ZSM-5, 30\% ZSM-5, 100\% ZSM-5 at $450{ }^{\circ} \mathrm{C}$. Key - others: blue, phenol: red, ketone: green, acid: purple, mono aromatics: light blue.

Figure 2 through figure 4 also shows as the fraction of ZSM-5 gradually increase, it will also increase the yield of mono aromatic chemical compound in the sample. It is shown by the increasing yield of mono aromatics chemical compound as the fraction of ZSM-5 catalyst increased starting from $15 \%, 30 \%$, and finally $100 \%$. At the point of where the fraction of ZSM-5 is $100 \%$, it produced the highest yield of mono aromatics. It means, ZSM-5 catalyst, a zeolite-based catalyst, has the advantages of shape-selective reaction, which it can maximize the production of mono aromatics compound.

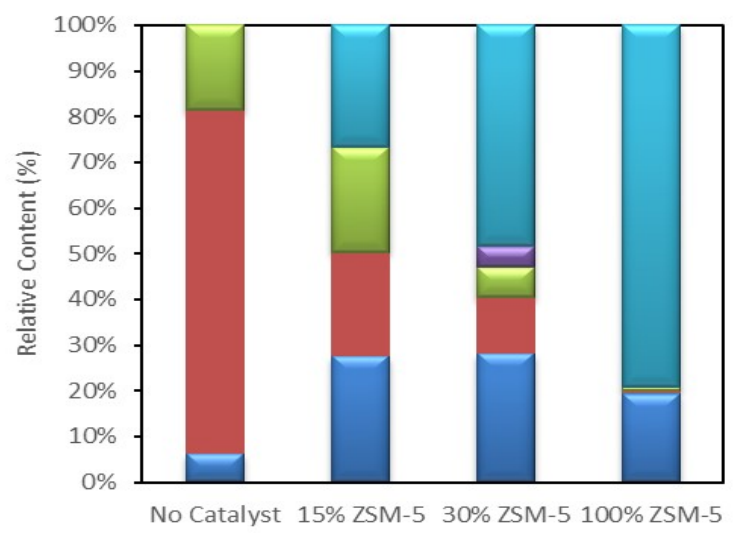

Fig. 3. Product distribution from catalytic conversion of biomass over three different composition of ZSM-5/ $\mathrm{B}_{2} \mathrm{O}_{3}$ catalysts: $15 \%$ ZSM-5, 30\% ZSM-5, $100 \%$ ZSM-5 at $475{ }^{\circ} \mathrm{C}$. Key — others: blue, phenol: red, ketone: green, acid: purple, mono aromatics: light blue

It is found that H-ZSM-5 catalyst have a high performance in the formation monoaromatic compounds. Therefore, the use of H-ZSM-5 without addition of boron oxides is observed more detailed to obtain the distribution of the monoaromatics compounds produced.

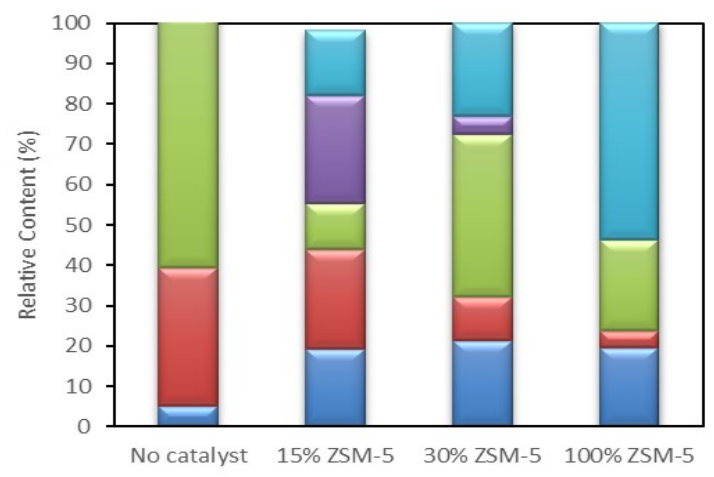

Fig. 4 Product distribution from catalytic conversion of biomass over three different composition of ZSM-5/ $\mathrm{B}_{2} \mathrm{O}_{3}$ catalysts: $15 \% \mathrm{ZSM}-5,30 \% \mathrm{ZSM}-5,100 \% \mathrm{ZSM}-5$ at $500^{\circ} \mathrm{C}$. Key - others: blue, phenol: red, ketone: green, acid: purple, mono aromatics: light blue.

The results can be seen from the Fig. 5 for reaction at 450 ${ }^{\circ} \mathrm{C}$, Fig. 6 for reaction at $475{ }^{\circ} \mathrm{C}$ and the reaction at $500{ }^{\circ} \mathrm{C}$ shown in Fig. 7. It can been concluded that the monoaromatics compound with the highest yield for all samples is 1,3 dimethylbenzene or $\mathrm{m}$-xyelene.

1,3-dimethylbenzene is consistencely presence in the three samples with the highest yield. The yield of 1,3 Dimethyl benzene produced from the result of catalytic conversion process of rice straw using 100\% HZSM-5 catalyst under the temperature 450 OC is $23.95 \%$ peak area. Then, when the operation temperature was raised from $450{ }^{\circ} \mathrm{C}$ to $475 \mathrm{C}$, while using the same composition of $100 \%$ HZSM-5 it yielded $18.71 \%$ of 1,3 Dimethyl benzene. The yield of 1,3 Dimethyl benzene produced from the result of catalytic conversion process of rice straw under the temperature $500 \mathrm{C}$ is $25.75 \%$. 


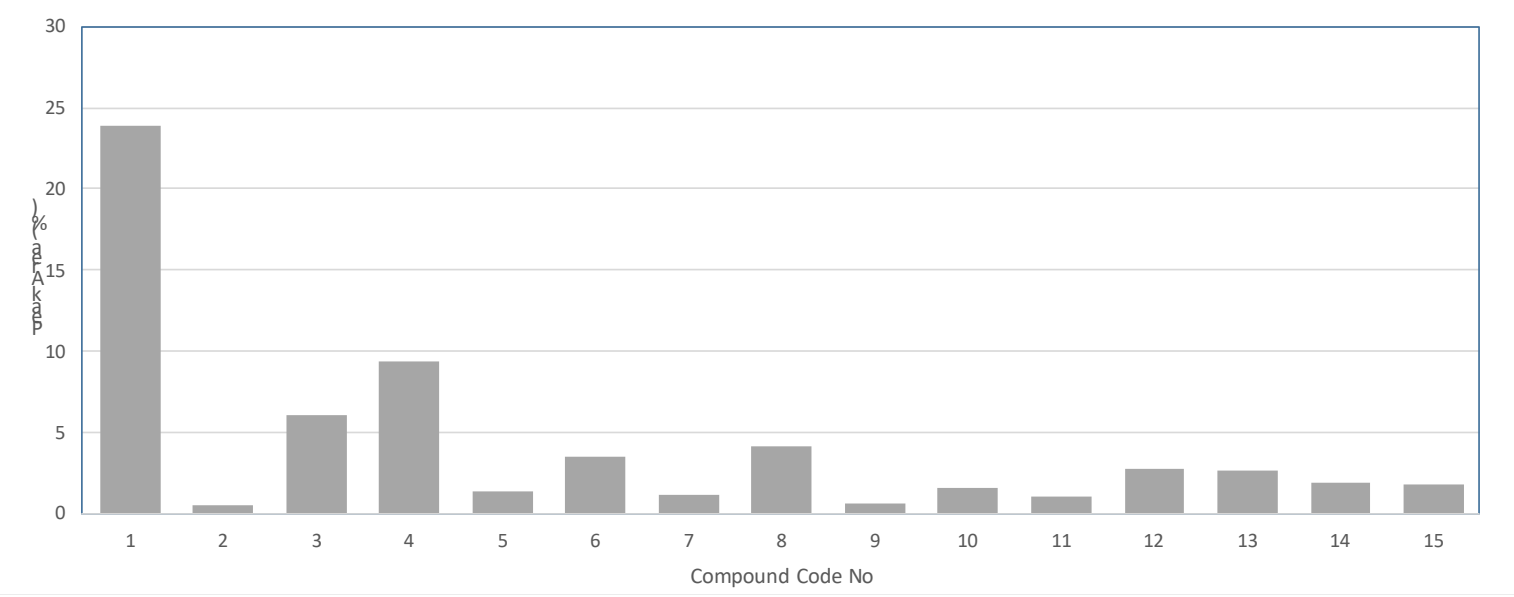

Fig. 5. Monoaromatics product distribution resulted from the catalytic conversion of rice straw using $100 \% \mathrm{H}-\mathrm{ZSM}-5$ at 450 ${ }^{\circ} \mathrm{C}$, Code No :

$\begin{array}{ll}1 & 1,3 \text {-dimethylbenzene/m-xylene } \\ 2 & n \text {-propylbenzene } \\ 3 & 1 \text {-ethyl-2-methylbenzene } \\ 4 & 1,2,3 \text {-trimethylbenzene } \\ 5 & \text { o-diethylbenzene }\end{array}$

6 1-propynylbenzene

7 diethylbenzene

8 2-methyl-1-propenylbenzene

9 1,2,4,5-tetramethylbenzene 1-methyl-2cyclopropen-1yl10 benzene
11 1-methyl-2-(1-methyl-2-propenyl-indene

12 2,3-dihydro-1H-indene

13 2,3-dihydro-5-methyl-1H-indene

14 2-methylindene

15 4,7-dimethyl-1H-indene

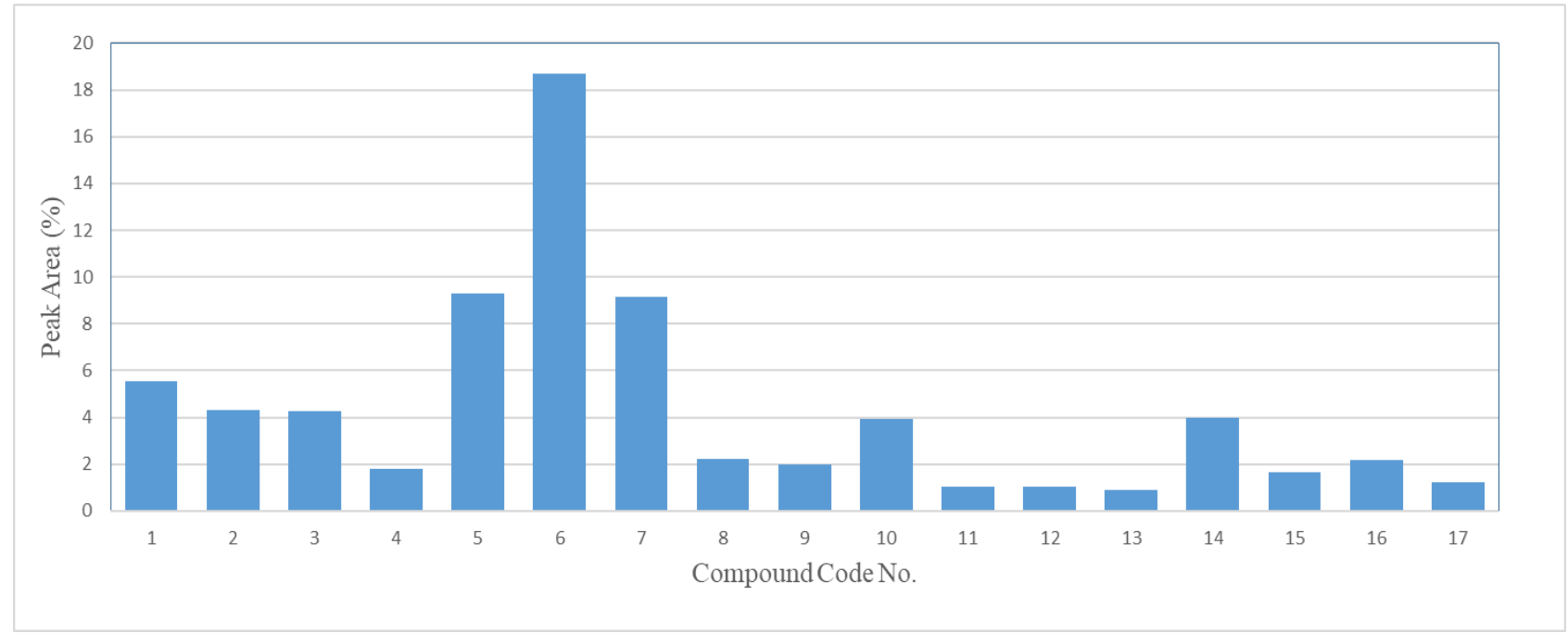

Fig. 6. Monoaromatics product distribution of catalytic conversion process of Rice straw using $100 \% \mathrm{H}-\mathrm{ZSM}-5$ at $475^{\circ} \mathrm{C}$, Code No :

$\begin{array}{ll}1 & \text { ethylbenzene } \\ 2 & \text { 1,4-dimethylbenzene } \\ 3 & \text { Ethenylbenzene/Styrene } \\ 4 & \text { n-propylbenzene } \\ 5 & \text { 1,2,3-trimethylbenzene } \\ 6 & \text { 1,3-dimethylbenzene/m-xylene }\end{array}$
7 1-ethyl-2-methylbenzene

8 cyclopropylbenzene

9 diethylbenzene

10 methy (1-methylethyl) benzene

11 1,2,3,5-tetramethylbenzene

12 2-Methyl-2 cyclopropen-1-yl benzene
13 1-methyl-1-butenylbenzene

14 Indene

15 2,3 Dihydro-5-methyl-H-indene

16 2-methylindene

17 1,3-dimethyl-1H-Indene 


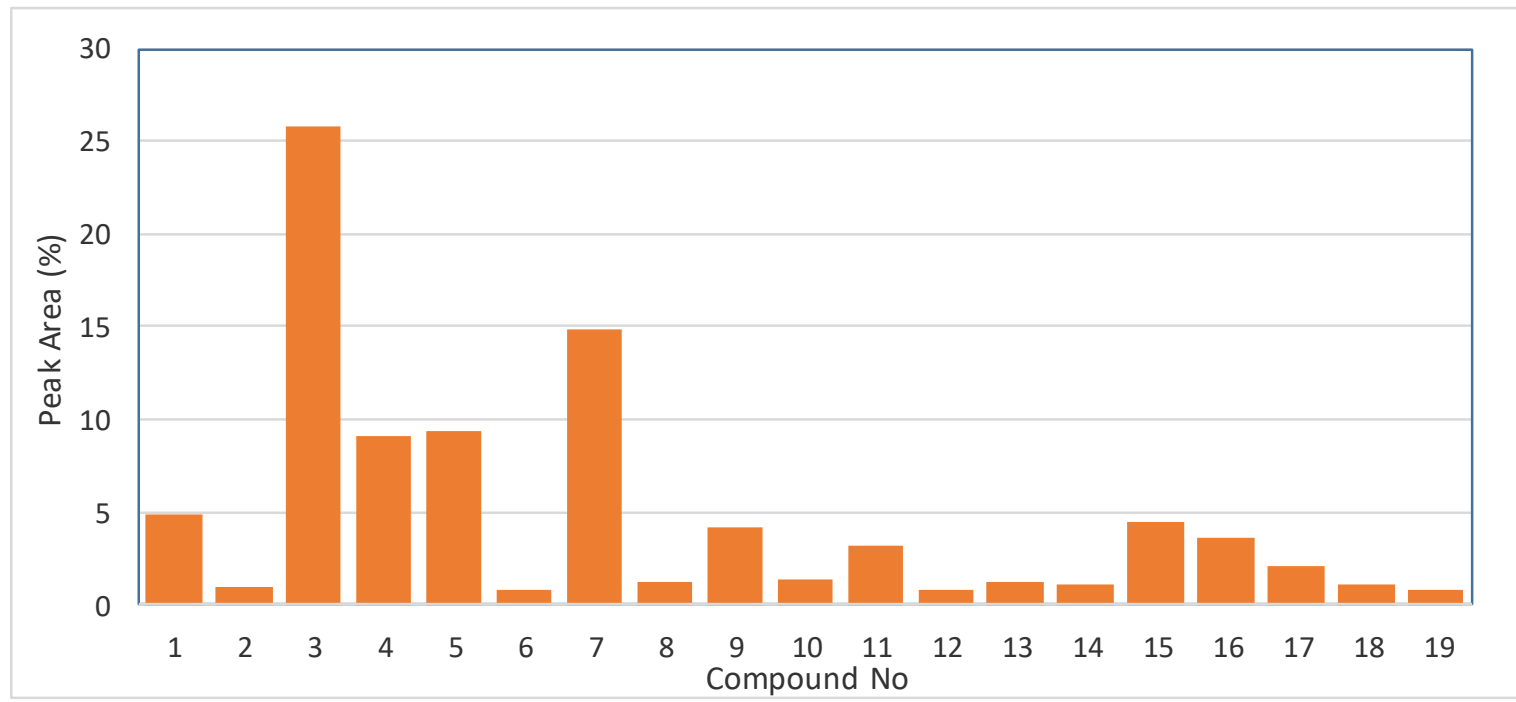

Fig. 7. Monoaromatics product distribution for catalytic conversion process of rice straw using $100 \%$ ZSM-5 at $500^{\circ} \mathrm{C}$, Code No :

$\begin{array}{ll}1 & \text { ethylbenzene } \\ 2 & \text { Propylbenzene } \\ 3 & \text { m-xylene } \\ 4 & \text { o-Xylene } \\ 5 & \text { 1-ethyl-2-methylbenzene } \\ 6 & \text { 1-ethyl 3-methylbenzene }\end{array}$

The data also implies that the presence of $\mathrm{B}_{2} \mathrm{O}_{3}$ in the mixture of the catalyst have no significant effect on the product distribution of the monoaromatics. The reason why that the presence of $\mathrm{B}_{2} \mathrm{O}_{3}$ in the mixture of the catalyst have no significant effect on the product distribution of the mono-aromatic compounds is due to the mixing process of HZSM- 5 catalyst and $\mathrm{B}_{2} \mathrm{O}_{3}$ wasn't done using the proper method. There are several methods for catalyst mixing, which one of the best way is by impregnation [5]. Impregnation is a process where the porous support is impregnated with a solution of a compound of the desired catalytic constituent.

According to a research done by Asaftei, et al.[6] which was the conversion of Butane-Butylene mixtures into more valuable aromatic rich hydrocarbons over HZSM-5 and boric acid prepared by impregnation technique, suggested that the boric acid (oxide precursor of $\mathrm{B}_{2} \mathrm{O}_{3}$ ) impregnation of HZSM-5 zeolite may narrows the pore openings, so the specific active area is decreased. The dispersion of $\mathrm{B}_{2} \mathrm{O}_{3}$ that takes place inside the pores and outside on the surface of HZSM- 5 leads to the formation of monolayer of $\mathrm{B}_{2} \mathrm{O}_{3}$. The presence of $\mathrm{B}_{2} \mathrm{O}_{3}$ particles changed the diffusivity of hydrocarbons by reducing the number of accessible active sites. The changes of both diffusivity and acidity enhance the shape selectivity. The mono layer of $\mathrm{B}_{2} \mathrm{O}_{3}$ inside the pores of HZSM-5 blocked most of the bronsted acid sites. Then, the HZSM-5 catalyst with the addition of boron species proves to be useful in conversion process to produce aromatics such as benzene, toluene, and xylene compounds. While in this research, the mixing process of the HZSM-5 and $\mathrm{B}_{2} \mathrm{O}_{3}$ catalyst was only done by physical mixing using mortar and pestle.

The preparation of catalyst by physical mixing, it suggested that the $\mathrm{B}_{2} \mathrm{O}_{3}$ catalyst was low homogeneous mixed and the particle in low dispersion throughout the surface pores of HZSM-5 catalyst. Due to this low dispersion, $\mathrm{B}_{2} \mathrm{O}_{3}$ catalyst led to the accumulation of $\mathrm{B}_{2} \mathrm{O}_{3}$ catalyst in the mouth of the pores of HZSM-5 catalyst instead of reducing some of the active sites of the HZSM-5 catalyst to enhance the shape selectivity of the HZSM-5catalyst. Shafagat [7] reported that the toluene was produced from the direct hydrodeoxygenation of cresol (methyl-phenol). Toluene then with the help of zeolites properties of the ZSM-5 catalyst, will be converted to 1,3 Dimethyl benzene or m-xylene through the reaction of trans alkylation. Meshram [8] also reported that ZSM-5 zeolites possess high selectivity and stability in the transalkylation reaction. So, it explains how the high yield of 1,3 Dimethyl benzene was produced.

\section{Conclusions}

The catalytic conversion of rice straw with ZSM-5 catalyst and its mixture with $\mathrm{B}_{2} \mathrm{O}_{3}$ with different fraction of ZSM-5 and $\mathrm{B}_{2} \mathrm{O}_{3}$ resulted in the production of mono 
aromatics compound. Monoaromatics compound can be produced through catalytic conversion process of rice straw using the mixture of HZM- 5 and $\mathrm{B}_{2} \mathrm{O}_{3}$ catalyst under 450,475 , and $500{ }^{\circ} \mathrm{C}$ in the atmospheric operating condition. The products resulted from the catalytic conversion of the rice straw can be distributed in to 4 major chemicals compound groups which are phenol compounds, ketone compounds, mono aromatic compounds, acid compounds, and other chemical compounds. The catalytic conversion of the rice straw using $100 \%$ HZM-5 catalyst under the temperature of $450{ }^{\mathrm{O}} \mathrm{C}$ yielded $63.11 \%$ mono aromatic compounds. With the operating temperature of $475{ }^{\circ} \mathrm{C}$, it yielded $73.21 \%$. And the operating temperature of $500{ }^{\mathrm{O}} \mathrm{C}$ yielded $91.33 \%$ of aromatic compounds. The yield of mono aromatic compounds will increase as the amount of fraction of HZM-5 in the mixture of HZM-5 and $\mathrm{B}_{2} \mathrm{O}_{3}$ catalyst, and the operating temperature also increased.

The authors would like to acknowledge the grant "Publikasi Internasional Terindeks untuk Tugas Akhir Mahasiswa" (PITTA) Universitas Indonesia with Grant number 2526/UN2.R3.1/HKP.05.00/ 2018 for the financial support during the research.

\section{References}

[1] F.X. Collard, J. Blin, Renew. and Sustain Energy Reviews 38, pp. 594-608 (2014)

[2] L. Zhang, C. Xu, P. Champagne, Energy Convers. Manag., 51 (5) (2010) 969-982.

[3] S. Cheng, L. Wei, X. Zhao, J. Julson, Catalysts, 6 pp. 195 (2016).

[4] T. Carlson, J. Jae, G.W. Huber, Chem.Cat.Chem, 1 (1), pp. 107-110 (2009)

[5] Dewajani, H., Rochmadi., Parwono, S., and Budiman, A. AIP Conference Proceedings 1755, 050002 (2016).

[6] Asaftei, Iuliean V., et al. (2012).REV. CHIM., 63, No.10: 1035-1041

[7] H. Shafaghat, P. S.Rezaei, Wan M. A. Wan Daud, RSC Adv, 5 (43), pp. 33990-33998 (2015)

[8] R.M. Meshram, S.B. Kulkarni, P. Ratnasamy, J. Chem.Tech. Biotechnol, 34A, pp. 119-126(1984) 